\title{
Family communication matters: The impact of telling relatives about unclassified variants and uninformative DNA-test results
}

\author{
Joël Vos, MA, MSc ${ }^{1}$, Anna M. Jansen, $M S c^{1}$, Fred Menko, MD, PhD ${ }^{2}$, \\ Christi J. van Asperen, MD, PhD ${ }^{I}$, Anne M. Stiggelbout, MA, PhD , and Aad Tibben, MA, PhD ${ }^{1,4}$
}

\begin{abstract}
Background: Unclassified variant and uninformative $B R C A 1 / 2$ results are not only relevant for probands to whom results are disclosed but also for untested relatives. Previous studies have seldomly included relatives and have not explained how their lives were influenced by these results. We explored the family communication timeline of genetic counseling: (1) genetic counselors communicate the relatives' cancer risk, (2) probands perceive this risk and (3) communicate this to relatives; (4) relatives perceive this information, and (5) experience an impact on their lives. Methods: We conducted a retrospective descriptive study in 13 probands with an unclassified variant and 5 with an uninformative result, and in, respectively, 27 and 12 of their untested female relatives from moderate cancer risk families. In questionnaires, probands described their perception of the DNA-test result (i.e., recollections and interpretations of cancer risks and heredity likelihood). Relatives described the communication process, their perception, and impact (i.e., medical decisions, distress, quality of life, and life changes). Bootstrap analysis was used to analyze mediation effects. Results: The relatives' own perception strongly predicted breast selfexamination, breast/ovarian surveillance or surgery, levels of distress and quality of life, and amount of reported life changes. The extent to which the proband had communicated the DNA-test result in an understandable, direct, reassuring way, predicted the relatives' perception. The actual communicated relatives' cancer risks or the proband's perception did not predict relatives' perception and impact measures. Family characteristics influenced the communication process but not the relatives' perception and outcomes. Discussion: Relatives seem to make poorly informed decisions on the basis of their own perception, which was unrelated to the information that probands had communicated on the basis of the actual communicated result. Therefore, genetic counselors may guide probands in the communication process and may directly inform relatives, if possible. Genet Med 2011:13(4):333-341.
\end{abstract}

Key Words: BRCA1/2, oncology, psychology, genetic counseling, family therapy

\section{INTRODUCTION}

Results of genetic counseling and testing are not only relevant for the tested proband but also for her relatives. ${ }^{1,2}$ The detection of

From the ${ }^{1}$ Department of Clinical Genetics, Center for Human and Clinical Genetics, Leiden University Medical Center, Leiden; ${ }^{2}$ Department of Clinical Genetics, VU University Medical Center, Amsterdam; ${ }^{3}$ Department of Medical Decision-Making, Leiden University Medical Center, Leiden; and ${ }^{4}$ Department of Clinical Genetics, Erasmus Medical Centre, Rotterdam, The Netherlands.

Joël Vos, MA, MSc, P.O. Box 9600, Leiden 2300 RC, The Netherlands. E-mail: j.vos@lumc.nl.

Disclosure: The authors declare no conflict of interest.

Submitted for publication July 26, 2010.

Accepted for publication October 29, 2010.

Published online ahead of print February 24, 2011.

DOI: $10.1097 /$ GIM.0b013e318204cfed a pathogenic mutation (PM) in a proband, i.e., the first tested in the family, has unequivocal implications: the deleterious mutation in the proband suggests that cancer in the family is caused by a genetic predisposition, and relatives have high a priori cancer risks. Subsequently, a relative could be tested for the PM that was detected in the proband, and on the basis of this DNA-test result, the genetic counselor could advise her to undergo surveillance or surgery of breasts/ovaries. When no PM is detected in the proband, the genetic counselor may calculate a priori cancer risks for relatives, and relatives could be advised to undergo frequent surveillance of breasts/ovaries, but DNA testing is not an option.

What does the literature say about the impact of DNA testing in untested relatives? The few studies in this field have not directly asked relatives about the impact of DNA testing on their lives; only probands were asked about the impact on their relatives. ${ }^{3}$ These studies suggest that the communication of a DNA-test result may cause distress in relatives, especially in children, ${ }^{3-6}$ and may revive unresolved family myths, loyalty conflicts, and family-relational problems. ${ }^{7-9}$ Relatives seem more likely to undergo DNA testing after communication of a PM and are influenced by the emotional and behavioral characteristics of the communication process by the proband. ${ }^{3,10,11}$ One study showed relationships of the cancer-risk perceptions among sisters within pathogenic families. ${ }^{6}$

Most studies focused on the impact of PM results on relatives. It is unclear how families without a PM communicate about the DNA-test result, and how this communication process relates to the medical decisions and well-being of relatives. When no PM is found, either an uninformative result (UR) or unclassified variant (UV) may be difficult for probands to communicate and for relatives to understand. In contrast with PMs, UR/UV results do not imply clear information about the likelihood that cancer is heritable in the family and about the relatives' risks to develop cancer. The communicated heredity likelihood and cancer risks are calculated on the basis of the pedigree and are therefore less clear/unequivocal than PMs. Because of this unclearness of UR/UV results, relatives may not base their perception and medical decisions on the actual content of the result but on their own perception of the result and on communication processes between proband and relative. ${ }^{12}$

\section{General family communication timeline}

In this study, the impact of UR/UV results on relatives' lives is explored by describing the relatives' perception, medical decision making, psychological distress, quality of life, and amount of life changes. The family communication timeline of genetic counseling consists of five steps (see Fig. 1). ${ }^{12}$

First, a genetic counselor communicates genetic information to the proband: (1) DNA-test result category in this study: UV (a DNA mutation for which the clinical meaning is not known) or UR (no mutation was found in a family with high cancer 


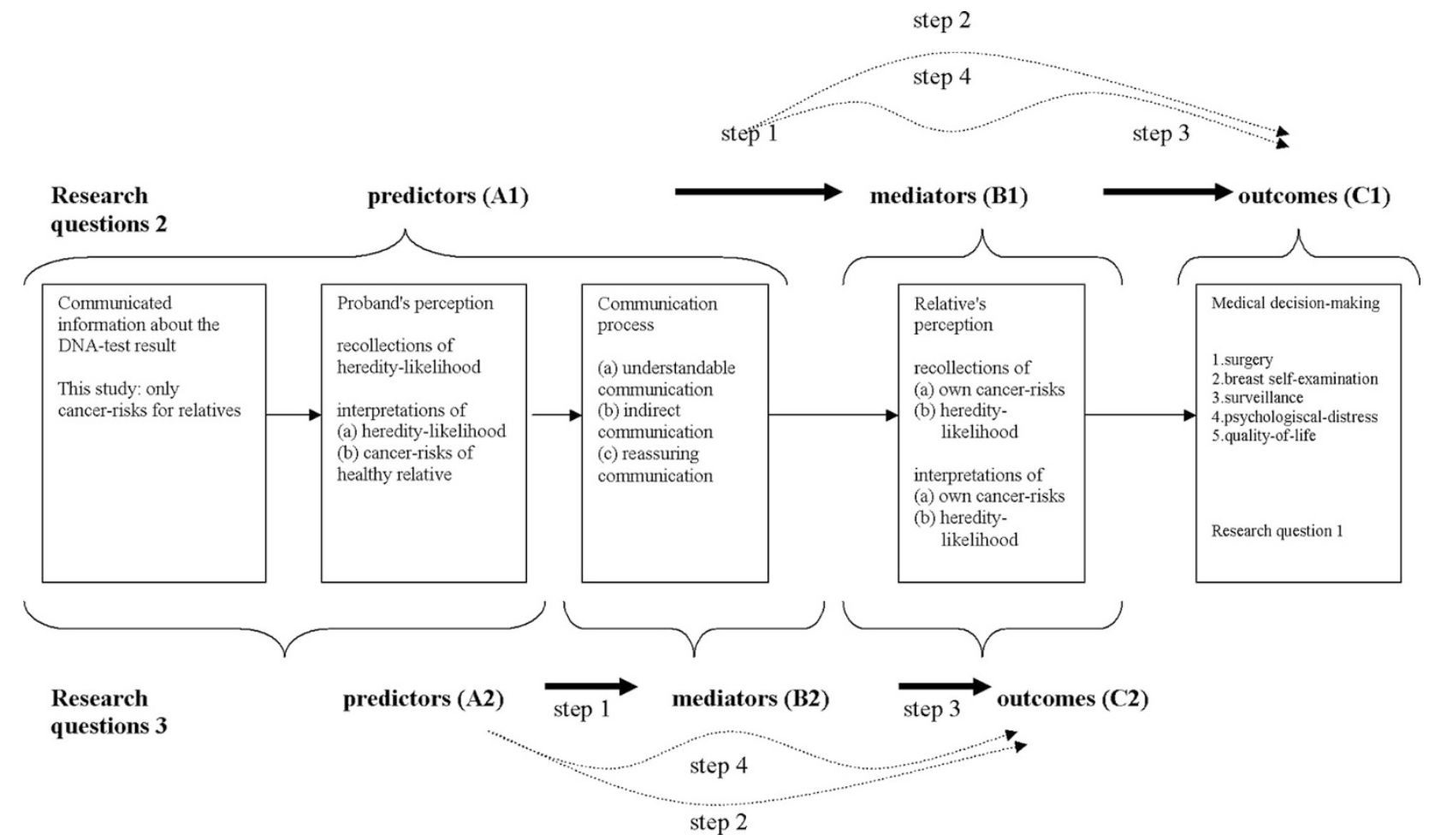

Fig. 1. The communication timeline of genetic counseling, showing all included variables and research questions of this article. Steps and dotted lines are mediation steps as explained in the "Method" section.

risks); (2) risk for developing ovarian cancer and/or contralateral breast cancer for the proband; (3) lifetime cancer risks for relatives of the proband; (4) the likelihood that cancer is heritable in the family, i.e., heredity likelihood. This study only included UR/UV results and focused on the communicated cancer risks for relatives.

Second, the proband perceives the communicated information. We operationalize "perception" as a person's recollections and interpretations of DNA-test result category, cancer risks, and heredity likelihood. ${ }^{13,14}$ This perception has shown to be inaccurate in many probands, and significant differences exist between the actual communicated information and the proband's perception of the DNA-test result. ${ }^{12,14}$

Third, the probands may communicate the DNA-test result to their relatives. This communication process can be described in two ways. First, they may communicate facts, such as cancer risks and heredity likelihood. Second, they may communicate emotional and psychosocial processes. For instance, probands and relatives may discuss their worries and feelings of uncertainty about the cancer risks for all involved and their feelings about inheritance and cancer. ${ }^{15}$ A proband may provide social support and be open, or instead be closed, nonsupportive and avoidant in the communication..$^{3,15-17}$ These communication processes between proband and relative could be influenced by family-relational characteristics such as level of openness to discuss cancer. ${ }^{1,2,18}$

Fourth, relatives recall and interpret the information that the proband has communicated about their cancer risks and heredity likelihood. Our previous study showed that the relatives' perception differed significantly from their proband's perception and correlated poorly with their proband's perception. ${ }^{12}$ This finding suggests that genetic information is generally not accu- rately transferred between proband and relatives similar to a children's whisper game.

Fifth, the relatives' perception may influence outcome variables of relatives: medical decisions, psychological distress, quality of life, and life changes.

\section{Research questions}

1. What is the impact of DNA-test result disclosure on the lives of untested relatives from UR/UV families, i.e., medical decisions, psychological distress, quality of life, and number of life changes?

2. In UR/UV families, is the impact on relatives: (a) directly predicted by the actual communicated relatives' cancer risks and the proband's perception; (b) mediated by the relatives' perception; and (c) only predicted by the relatives' perception?

3. In UR/UV families, is the relatives' perception: (a) directly predicted by the actual communicated relatives' cancer risks and the proband's perception; (b) mediated by the communication process; (c) only predicted by the communication process?

4. Do family characteristics (openness to discuss hereditary cancer in the family, relationship/involvement between proband and relative, and pedigree) predict the communication process but not the perception and outcomes of relatives?

\section{METHOD}

\section{Procedure}

Eligible participants, in this study, were probands from families with intermediate or high cancer risks who had received a 
BRCA1/2 DNA-test result in the period 1998-2008 at the Leiden University Medical Center or the VU Medical Center Amsterdam. ${ }^{13,14}$ Because the primary focus of our study concerns UVs, we first approached probands with UVs, communicated as "a mutation/genetic change for which the clinical meaning is not known (yet)." In addition, we approached women with UR results, with matching year of result disclosure.

Overall, 18 of 55 contacted probands with UR/UV results agreed that we approached their first-degree and/or seconddegree relatives in the affected branch of the family (33\%), 24 probands (44\%) did not respond, and 13 (23\%) declined. Subsequently, in line with the proband's preference, we sent our invitation letter either to relatives directly or to the proband who distributed the letters. We approached 91 relatives; 49 of them participated (54\%), 30 (33\%) did not respond, and 12 declined (13\%); 8 participants were excluded because they had requested a DNA test for themselves or were male. Analysis of which probands declined, did not react, or agreed on participation did not show significant predictors; familial characteristics did also not predict which relatives declined, reacted, or agreed (i.e., all instruments in Table 1 in the proband's questionnaire).

The study was approved by the medical ethical committees of the participating medical centers. Details on procedure and sample are described elsewhere. ${ }^{12,13}$

\section{Instruments and analyses}

Questions about the proband's and relatives' perception were developed in previous studies ${ }^{12,14}$ and are depicted in Table 1.

Communication process variables were developed on the basis of clinical experience. ${ }^{23,24}$ To reduce the number of variables, principal component analyses (PCA) with multiple imputing for missing values were performed on the communication process. Varimax rotation was performed for interpretability of components. Number of components was decided on the basis of the eigenvalues, scree plot, interpretability, and good Cronbach's alpha. Psychological outcomes (3), ${ }^{19}$ quality of life, ${ }^{20}$ and total amount of life changes ${ }^{14,25}$ were measured with valid, reliable scales; reliability was confirmed with Cronbach's alphas.

Question 1: sample and outcome variables were described with frequencies and means $(m, \mathrm{SD})$. In line with our previous studies, ${ }^{14}$ questions 2,3 , and 4 were analyzed with mediation analyses by bootstrapping, ${ }^{26}$ which is a relatively robust technique. ${ }^{27}$ Mediation is present when variable $\mathrm{B}$ mediates the relationship between variables $\mathrm{A}$ and $\mathrm{C}$, and four mediation steps are fulfilled. (1) Variables A and B significantly correlate (A\&B). (2) Variable B significantly predicts variable $\mathrm{C}(\mathrm{B} \rightarrow \mathrm{C})$. (3) Variable A significantly predicts variable $C(A \rightarrow C)$. (4) When variable $\mathrm{B}$ is included in bootstrapping analyses, A explains $\mathrm{C}$ to a lesser extent, when compared with step 3 $(\mathrm{A} \rightarrow \mathrm{B} \rightarrow \mathrm{C})$. Either the beta decreases but remains significant (i.e., "partial mediation") or the beta becomes nonsignificant (i.e., "complete mediation"). Mediation step 1 is not presented but assumed in each table in which steps 2, 3, and 4 are presented together.

We use the expression "direct effect" to indicate that A directly predicts $C$; the beta is not influenced by the inclusion of beta in analyses $(P$ value step $4>0.01)$. We use the expression "indirect effect" to indicate that A indirectly predicts $\mathrm{C}$, by partial or complete mediation by beta $(P$ value step $4<0.01)$. We use the expression "effect" without adjective to indicate the results from analyses between variables $\mathrm{A}-\mathrm{B}, \mathrm{A}-\mathrm{C}$, or $\mathrm{B}-\mathrm{C}$ in steps 1, 2, and 3. Linear regression analyses were used to calculate standardized betas, logistic regression in case of binary outcomes. Alpha was set at 0.01 , and 5000 bootstrap resamples were performed. ${ }^{26}$ Effect sizes were described with
Nagelkerke $(<0.20$ moderate; $0.20-0.40$ good, and $>0.40$ strong) or $f^{2}$ (0.02 small, 0.15 medium, and 0.35 large).

\section{RESULTS}

\section{Population}

We included 13 probands with UV results and 5 with UR results, and, respectively, $27(65 \%)$ and $12(35 \%)$ of their untested female relatives. Of the 41 relatives, $8(21 \%)$ had had breast cancer, diagnosed around 2002 (SD = 4 years). Twentyeight $(72 \%)$ had had higher education, $27(69 \%)$ had a job, and $9(23 \%)$ were religious; no significant differences were found between URs and UVs in demographics and cancer histories of probands and relatives. ${ }^{12,13}$

The originally communicated cancer risks were substracted for 32 relatives $(81 \%)$ from their proband's medical file; mean communicated relatives' risks were $20.4 \%$ ( $S D=15.3 \%)$; for comparison reasons only, we transformed this into 3.7 (SD = 1.0) on a 1- to 7-point scale. On 7-point scales, probands recalled mean heredity likelihood and relatives' cancer risks as 4.1 and 5.2, respectively, and interpreted heredity likelihood higher as 5.8. Relatives recalled mean cancer risks of 4.6 and heredity likelihood of 3.0; they interpreted both higher as 4.5 and 3.6 (Table 2).

\section{Preparatory analyses}

PCA yielded three components for the communication process (respectively, variances accounted for $=0.44,0.15$, and $0.11 ; \alpha=0.90,0.70$, and 0.85). Component 1 (four items) measured "understandable communication," i.e., the extent to which the proband explained the DNA-test result in an understandable way to the relative. Component 2 (four items) measured "indirect communication," i.e., the extent to which the proband communicated the DNA-test result indirectly to the relative. Component 3 (three items) measured "reassuring communication," i.e., the extent to which the proband communicated the DNA-test result in a reassuring or soothing way. The variable "poor/good explanation" loaded high on both indirect and reassuring communication and low on understanding, which suggests that relatives base their total evaluation of the quality of the explanation more on the process of communication than on the content of communication. Interpretation of these three components was confirmed by correlations with other variables (not described in this study) (Table 3).

The scales for psychological distress, quality of life, and number of life changes resulted from PCA analysis, which showed good reliability of $0.81,0.92$, and 0.85 , respectively (cf. Table 1).

\section{Question 1: Outcomes}

Four of the eight affected relatives $(50 \%)$ had undergone contralateral prophylactic mastectomy after the proband's DNA testing, and 4 of the 33 unaffected relatives (12\%) had undergone prophylactic mastectomy. Thirty-two $(82 \%)$ of both affected and unaffected women had performed breast self-examination during the last 6 months and $21(54 \%)$ surveillance of breasts and/or ovaries by a physician. Mean psychological distress was 29.3, which is low on the scale range of 19-76; three relatives $(8 \%)$ reported large distress larger than 57 . Mean quality of life was 15.3 , which is moderately high on the scale range of 4-20; eight relatives (21\%) reported low quality of life lower than 10. Relatives reported that their lives had somewhat changed regarding medical and psychological aspects (13.5); 11 (28\%) reported large changes larger than 15 . Outcomes did not 


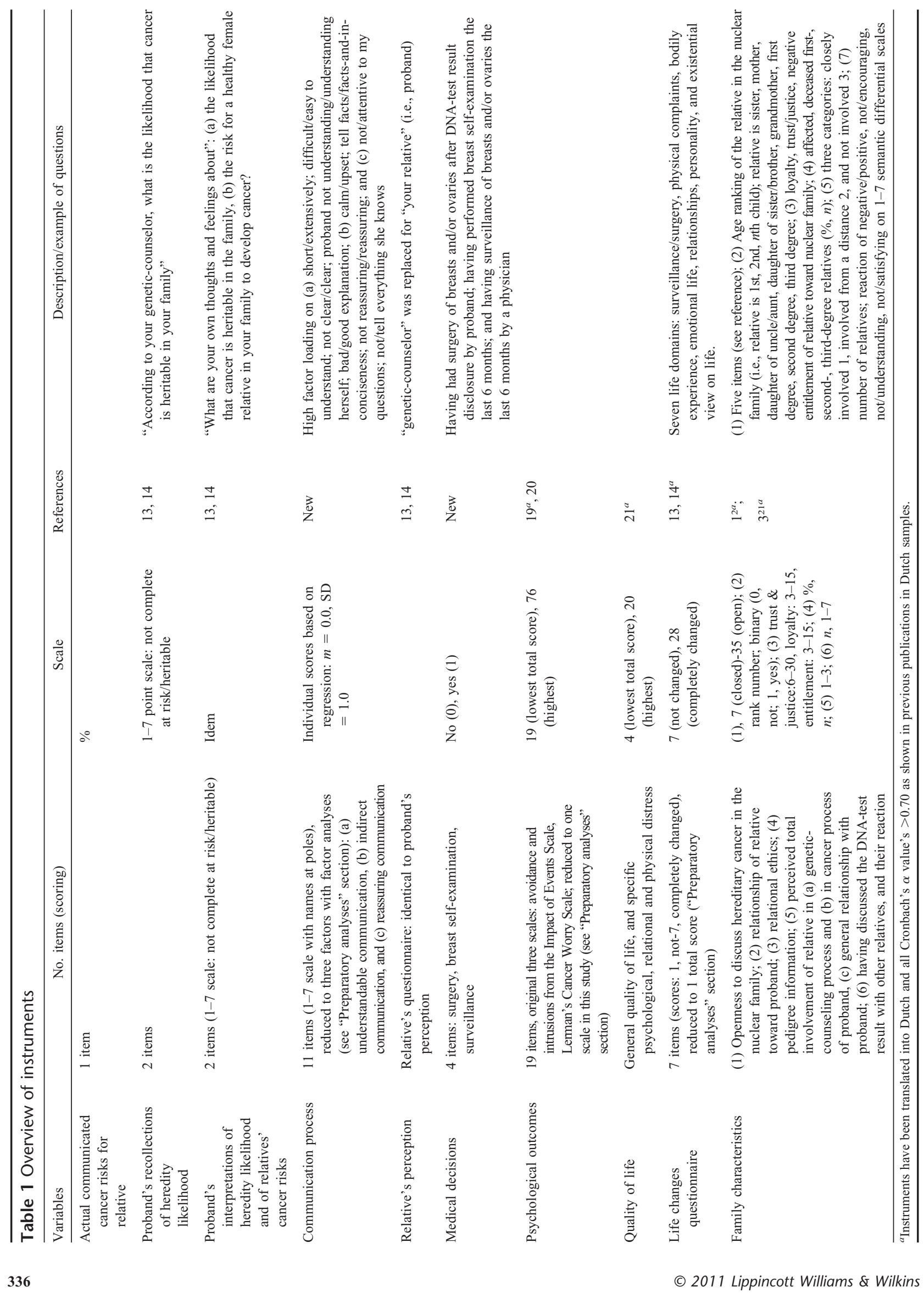


Table 2 Overview of variables in the family communication timeline

\begin{tabular}{lll}
\hline Variables & $M(\mathrm{SD})$ & $N(\%)$ \\
\hline Actual communicated information & & \\
$\quad$ Relatives' cancer risks & $20.4(15.3)$ & \\
Unclassified variant & & $27(63)$ \\
Uninformative result & & $14(37)$ \\
Proband's perception & & \\
Recalled heredity likelihood & $4.1(1.7)$ & \\
Interpreted heredity likelihood & $5.8(1.5)$ & \\
Interpreted relatives' cancer risks & $5.2(1.1)$ & \\
Relatives' perception & & \\
Recalled cancer risks & $4.6(1.0)$ \\
Recalled heredity likelihood & $3.0(1.3)$ & \\
Interpreted cancer risks & $4.5(0.9)$ \\
Interpreted heredity likelihood & $3.6(1.2)$ & \\
\hline
\end{tabular}

significantly differ between affected and unaffected relatives (Table 4).

\section{Question 2: Prediction of medical decisions}

Only significant correlations between A and B from step 1 were used in mediation steps $2-4$, which are presented in Table 5 (Fig. 1).

\section{Step $2(B 1 \rightarrow C 1)$}

The relatives' perception directly predicted all outcome measures with moderate to strong effect sizes. Interpreted heredity likelihood predicted surgery, and recalled and interpreted heredity likelihood predicted breast self-examination. Recalled and interpreted cancer risks and interpreted heredity likelihood predicted surveillance. Recalled and interpreted cancer risks
Table 4 Description of outcome-variables in relatives

$N(\%)$

$39(1.00)$ $M(\mathrm{SD})$

Surgery

General

Presymptomatic

$4 / 31(0.13)$

Symptomatic

Breast self-examination

Surveillance by physician

$21(0.54)$

Psychological distress

Quality of life

Total amount of life changes

$13.5(5.8)$

See Table 1 for description of the scales.

predicted psychological distress and life changes. Recalled and interpreted heredity likelihood predicted quality of life.

\section{Step $3(A 1 \rightarrow C 1)$}

The actual communicated relatives' cancer risks and proband's perception did not predict any outcomes.

Step $4(A 1 \rightarrow B 1 \rightarrow C 1)$

There was no mediation. In summary, the relatives' own perception was the only predictor of outcome variables.

\section{Question 3: Prediction of relatives' perceptions}

Only significant correlations between A and B from step 1 were used in mediation steps 2-4, which are presented in Table 6.

Step $2(B 2 \rightarrow C 2)$

The communication process predicted all perception variables with large effect sizes. Understandable, indirect, and reassuring communication together predicted the relatives' recollection of cancer risks. Reassuring communication was the only

Table 3 Results of principal component analyses, Varimax rotation with Kaiser normalization

\begin{tabular}{lccc}
\hline & \multicolumn{2}{c}{ Component } \\
\cline { 2 - 4 } & $\begin{array}{c}\text { 1: Understandable } \\
\text { communication }\end{array}$ & $\begin{array}{c}\text { 2: Indirect } \\
\text { communication }\end{array}$ & $\begin{array}{c}\text { 3: Reassuring } \\
\text { communication }\end{array}$ \\
\hline Short/extensive & 0.356 & 0.581 & 0.102 \\
Difficult/easy to understand & 0.937 & 0.046 & 0.050 \\
Calm/upset & -0.257 & 0.217 & -0.648 \\
Not clear/clear & 0.882 & 0.266 & 0.172 \\
Proband did not understand/did understand the result herself & 0.847 & 0.681 & 0.096 \\
Only tell facts/tell facts and emotions & 0.110 & 0.108 & 0.900 \\
Not reassuring/reassuring & 0.067 & 0.640 & 0.254 \\
Not attentive/attentive to my questions & 0.411 & 0.366 & 0.194 \\
She seemed not to tell everything/seemed to tell everything & 0.655 & 0.597 & 0.541 \\
Bad/good explanation & 0.255 & & \\
\hline
\end{tabular}


Table 5 Results for research question 2

\begin{tabular}{|c|c|c|c|c|c|c|c|}
\hline \multirow[b]{2}{*}{$\begin{array}{l}\text { Predicted outcome } \\
\text { variables } \mathrm{C} 1\end{array}$} & \multirow[b]{2}{*}{$\begin{array}{l}\text { Predictors } \\
\text { A1 }\end{array}$} & \multicolumn{4}{|c|}{ Mediator(s) B1 } & \multicolumn{2}{|c|}{$\begin{array}{l}\text { Total model } \\
\text { statistics }\end{array}$} \\
\hline & & $\begin{array}{l}\text { Recalled } \\
\text { cancer risk }\end{array}$ & $\begin{array}{l}\text { Interpreted } \\
\text { cancer risk }\end{array}$ & $\begin{array}{l}\text { Recalled heredity } \\
\text { likelihood }\end{array}$ & $\begin{array}{l}\text { Interpreted heredity } \\
\text { likelihood }\end{array}$ & Nagelkerke & $f^{2}$ \\
\hline \multicolumn{8}{|l|}{ Direct effect: $\mathrm{A} 1 \rightarrow \mathrm{C} 1$} \\
\hline $\mathrm{X}$ & NS & NS & NS & NS & NS & NS & NS \\
\hline \multicolumn{8}{|l|}{ Direct effect: $\mathrm{B} 1 \rightarrow \mathrm{C} 1$} \\
\hline Surgery & NS & NS & NS & NS & 1.1 & 0.32 & NS \\
\hline Breast self-examination & NS & NS & NS & 11.3 & 6.5 & 0.69 & NS \\
\hline Surveillance & NS & 2.0 & 5.4 & NS & 0.7 & 0.55 & NS \\
\hline Psychological distress & NS & 0.3 & 0.1 & NS & NS & NS & 0.13 \\
\hline Quality of life & NS & NS & 0.5 & NS & -0.3 & NS & 0.44 \\
\hline Total amount of life changes & NS & NS & NS & 0.4 & 0.7 & NS & 1.10 \\
\hline \multicolumn{8}{|l|}{ Indirect effect: $\mathrm{A} 1 \rightarrow \mathrm{B} 1 \rightarrow \mathrm{C} 1$} \\
\hline $\mathrm{X}$ & NS & NS & NS & NS & NS & NS & NS \\
\hline
\end{tabular}

Table 6 Results for research question 3

\begin{tabular}{|c|c|c|c|c|c|}
\hline \multirow[b]{2}{*}{ Predicted outcome variables $\mathrm{C} 2$} & \multirow[b]{2}{*}{$\begin{array}{l}\text { Predictor } \\
\text { A2 }\end{array}$} & \multicolumn{3}{|c|}{ Mediator(s) B2 } & \multirow[b]{2}{*}{$\begin{array}{l}\text { Total model } \\
\text { statistics, } f^{2}\end{array}$} \\
\hline & & $\begin{array}{l}\text { Understandable } \\
\text { communication }\end{array}$ & $\begin{array}{c}\text { Indirect } \\
\text { communication }\end{array}$ & $\begin{array}{c}\text { Reassuring } \\
\text { communication }\end{array}$ & \\
\hline \multicolumn{6}{|l|}{ Direct effect: $\mathrm{A} 2 \rightarrow \mathrm{C} 2$} \\
\hline $\mathrm{X}$ & NS & NS & NS & NS & NS \\
\hline \multicolumn{6}{|l|}{ Direct effect: $\mathrm{B} 2 \rightarrow \mathrm{C} 2$} \\
\hline Recalled cancer risks & NS & -0.42 & 0.53 & -0.35 & 1.00 \\
\hline Recalled heredity likelihood & NS & NS & NS & -0.59 & 0.52 \\
\hline Interpreted cancer risks & NS & -0.47 & NS & -0.26 & 0.42 \\
\hline Interpreted heredity likelihood & NS & NS & NS & -0.49 & 0.27 \\
\hline \multicolumn{6}{|l|}{ Indirect effect: $\mathrm{A} \rightarrow \mathrm{B} \rightarrow \mathrm{C}$} \\
\hline $\mathrm{X}$ & NS & NS & NS & NS & NS \\
\hline
\end{tabular}

Nonstandardized betas for medical decision making with linear regression. Only significant predictors, mediators, and total models are presented. All $P$ values $<$ 0.01.Constant and error terms are not presented to keep table simple. Nagelkerke is the effect size for binary outcomes, $f^{2}$ for linear scales. NS, not significant; direct effect $\mathrm{A} \rightarrow \mathrm{C}$ : communicated information or proband's perception predict relatives' perception $(\mathrm{A} \rightarrow \mathrm{C})$, inclusion of $\mathrm{B}$ has no sign effect. direct effect: $\mathrm{B} \rightarrow \mathrm{C}$ communication process predict relatives' perception $(\mathrm{B} \rightarrow \mathrm{C})$; indirect effect: mediation.

predictor of both recollections and interpretations of heredity likelihood. Understandable and reassuring communication predicted the interpretation of cancer risks.

\section{Step $3(A 2 \rightarrow C 2)$}

The actual communicated relatives' cancer risks and proband's perception did not predict any perception variables of the relatives.

\section{Step $4(A 2 \rightarrow B 2 \rightarrow C 2)$}

There was no mediation. In summary, the communication process was the only, strong predictor of the relatives' perception.

\section{Family characteristics}

Family characteristics did neither directly nor indirectly predict the relatives' perception and outcomes. The directness of the communication from proband to relative was predicted by the relative's perception of the family communication about 
Table 7 Results for research question 4

\begin{tabular}{|c|c|c|c|}
\hline & $\begin{array}{l}\text { Understandable } \\
\text { communication }\end{array}$ & $\begin{array}{c}\text { Indirect } \\
\text { communication }\end{array}$ & $\begin{array}{l}\text { Reassuring } \\
\text { communication }\end{array}$ \\
\hline Openness to discuss hereditary cancer in the nuclear family & NS & -0.42 & -0.33 \\
\hline Age ranking in the nuclear family, i.e., relative is 1 st, 2 nd, $n$th child & NS & -0.36 & NS \\
\hline Relative is sister of proband & NS & -0.28 & NS \\
\hline Loyalty of relative toward nuclear family & NS & 0.44 & NS \\
\hline Percentage affected first-degree relatives & NS & NS & -0.34 \\
\hline Percentage affected second-degree relatives & NS & NS & -0.53 \\
\hline Percentage affected third-degree relatives & NS & NS & -0.31 \\
\hline Involvement of relative in genetic-counseling process of proband & NS & -0.50 & NS \\
\hline Involvement of relative in cancer process of proband & NS & -0.32 & NS \\
\hline Closeness of relationship of relative toward proband & NS & -0.47 & NS \\
\hline
\end{tabular}

hereditary cancer as open, when she was a relatively younger sibling in the nuclear family, was the sister of the proband and felt more loyal to the nuclear family, and was more closely involved with the genetic counseling process, cancer process, and in general relationship with the proband. The extent to which the communication was experienced as reassuring was predicted by the relative's perception of the family communication about hereditary cancer as open and the percentage of affected first-, second-, and third-degree relatives (Table 7).

\section{DISCUSSION}

This is the first systematic study on the impact of DNA testing on the lives of untested relatives from UR/UV families. The impact on the medical decisions of relatives was remarkably high, given that most relatives were unaffected and were at moderate risk to develop cancer. They reported that their lives had somewhat changed regarding medical and psychological aspects. Eighty-two percent had performed breast self-examination and $54 \%$ surveillance by a physician. Twenty percent of all relatives had undergone mastectomy. Distress was low and quality of life moderately high; however, subgroups reported large distress and low quality of life.

The impact of the DNA-test outcome was strongly predicted by the relatives' own perception: the higher cancer risks and heredity likelihood were in the recollections/interpretations of relatives, the more radical were the medical decisions and the more negative the psychological distress and quality of life. The relatives' perception was strongly predicted by the way in which the proband had communicated the DNA-test result: the less understandable, direct and reassuring the communication was, the higher the cancer risks and heredity likelihood were in the relatives' perception. The actual communicated cancer risks of relatives and the proband's perception were not predictive of the relatives' perception and the impact in the relatives.

Family characteristics only predicted the way in which the proband had communicated the DNA-test result to the relative and did not predict the relatives' perception and outcomes. This suggests that family dynamics only influences how a family communicates about a DNA-test result but not how an individual relative feels and thinks about this result and its consequences. This could be explained by the fact that relatives may have developed their own strong, independent opinion about cancer risks and heredity likelihood because of their often lifelong history with cancer in the family. ${ }^{28-31}$

\section{Communication matters}

The results indicate that, as we hypothesized, relatives from UR/UV families do not base their medical decisions and psychological impact on communicated facts but on the communication process and their own perception. This is probably due to the complexity and lack of clarity of the UR/UV result.

The understandability and directness in which the proband had communicated the result predicted some aspects of the relatives' perception. However, the extent of reassurance provided by the proband predicted all aspects of the relatives' perception. This means that probands gave reassurance, independently from the content of the DNA-test result (confirmed by the fact that these variables were uncorrelated with the actual communicated cancer risks; results not shown). This reassurance could either have been accurate or inaccurate, from a genetic counselors' perspective. Probands are for instance accurate when they provide reassurance after a true-negative result (i.e., no mutation detected in a family with a known mutation) or when no reassurance is provided after a PM. They are inaccurate when they give false reassurance after a PM or when they provide no reassurance after a true-negative result.

On the one hand, communication by probands could have been expected to be neutral in our study, i.e., neither reassuring nor its opposite, because our sample consisted of mainly unaffected relatives from at-moderate risk families without a PM. On the other hand, the genetic counselor may not have communicated neutral information. Previous studies have shown that genetic counselors may feel uncertain about DNA-test results and may also nonverbally show their uncertainty to the counselees. ${ }^{32-35}$ This may especially be the case when no PM (UR/UV) is found, as was the case in our sample. We found that the proband's perception of their own and/or their relatives' cancer risk was often not in line with the objectively communicated facts, as reported in summary letters and medical files; however, their perception may be in line with the nonverbal communication of the genetic counselors. Probands may also have interpreted the uncertainty of the genetic counselor as a possibility to trust their own ideas and feelings instead of 
trusting the objectively communicated information. This may have led to a variety in the perceptions of both the probands and the relatives. However, we do not have data on these hypotheses.

Ad hoc analyses showed that, compared with URs, relatives perceived the communication of UVs as more indirectly and less reassuring (shown by unpresented, significant $t$ tests). Moreover, UVs were recalled/interpreted with somewhat higher cancer risks/heredity likelihood; much more relatives underwent surveillance and surgery ( $71 \%$ and $26 \%$ vs. $36 \%$ and $8 \%$ ), which was comparable with relatives who had been disclosed a PM $(85 \%$ and $50 \%) .{ }^{12}$ This seems to suggest that relatives perceived UVs as more pathogenic than URs, which is in line with the proband's perception. ${ }^{13,14}$

\section{Limitations}

This study is limited by its relatively small sample size, retrospective design, and relatively large number of hypothesized parameters. Causal relationships remain theoretically assumed and are not definitely proven. There may have been sample bias, because probands decided which relatives we were allowed to approach, and the relatives' participation percentage was low.

Selection bias could have occurred, because especially relatives who experienced a large impact of DNA testing on their medical behavior may have wanted to participate in this study. Only $33 \%$ of the probands and $54 \%$ of the relatives participated, which may limit representativeness of our sample; however, analyses of decline, nonresponse, and participation did not show significant predictors.

We did not present results for the relatives' sociodemographics and cancer history (affected, unaffected, breast and/or ovarian cancer, and metastases; kind of treatment and surveillance; and years of diagnoses), because these showed to be not significant predictors, mediators, and moderators in analyses of perception and outcomes.

\section{Implications}

We give the following suggestions for genetic counselors on the basis of the findings of this study, which need to be confirmed in larger studies. DNA testing is often relevant for relatives. Therefore, genetic counselors are advised to calculate and discuss cancer risks for specific relatives, and report this specifically in medical files and in the letters that they send to the proband and relatives. Of course, this may raise ethical and legal questions in countries where genetic information is expected to be restricted to the communication of the probands' risks only.

In this Dutch study, we discovered that specific cancer risks were infrequently reported in medical files and letters, and it was often unclear whose cancer risks were calculated (e.g., sister, daughter, cousin, and niece). This may have contributed to the inaccurate perceptions and impact of both probands and relatives.

Genetic counselors may explicitly support probands in disclosing DNA-test results and cancer risks accurately to relatives, ${ }^{36,37}$ especially in communicating this information in an understandable, direct way without giving false reassurance. Direct communication between counselor and relative may facilitate this process, and may contribute to improving the recollections and interpretations of relatives. For instance, genetic counselors could send a letter to all relatives with a summary of the DNA-test result and with the possibility for a personal consultation by phone or face to face.

\section{ACKNOWLEDGMENTS}

This study was supported by the Dutch Cancer Society (Grant no. UL2005-3214).

\section{REFERENCES}

1. van Oostrom I, MeijersHeijboer EJ, Duivenvoorden H, et al. A prospective study of the impact of genetic susceptibility testing for BRCA1/2 or HNPCC on family relationships. Psychooncology 2006;16:320-328.

2. van Oostrom I, Meijers-Heijboer EJ, Duivenvoorden H, et al. Family system characteristics and psychological adjustment to cancer susceptibility genetic testing: a prospective study. Clin Genet 2007;71:35-42.

3. Gaff CL, Clarke AJ, Atkinson P. Process and outcome in communication of genetic information within families: a systematic review (vol 15, pg 999, 2007). Eur J Hum Genet 2008;16:402.

4. Tercyak KP, Streisand R, Peshkin BN, Lerman C. Psychosocial impact of predictive testing for illness on children and families: challenges for a new millennium. J Clin Psychol Med Settings 2000;7:55-68.

5. Hughes C, Lerman C, Schwartz M, et al. All in the family: evaluation of the process and content of sisters' communication about BRCA1 and BRCA2 genetic test results. Am J Med Genet 2002;107:143-150.

6. Koehly LM, Peters JA, Kuhn N, et al. Sisters in hereditary breast and ovarian cancer families: communal coping, social integration, and psychological well-being. Psychooncology 2008; 17:812-821

7. Rolland JS. Cancer and the family: an integrative model. Cancer 2005;104: 2584-2595.

8. Douglas HA, Hamilton RJ, Grubs RE. The effect of BRCA gene testing on family relationships: a thematic analysis of qualitative interviews. $J$ Genet Couns 2009; 18:418-435.

9. Brown TC, Garber J, Muto M, Schneider KA. Case report-loyalty, legacy, and ledger: contextual therapy in a patient with a family history of ovarian cancer. J Genet Couns 1999;8:359-372.

10. Landsbergen K, Verhaak C, Kraaimaat F, Hoogerbrugge N. Genetic uptake in BRCA-mutation families is related to emotional and behavioral communication characteristics of index patients. Familial Cancer 2005;4:115-119.

11. Mellon S, Janisse J, Gold R, et al. Predictors of decision making in families at risk for inherited breast/ovarian cancer. Health Psychol 2009;28:38-47.

12. Vos J, Menko F, Jansen AM, van Asperen CJ, Stiggelbout AM, Tibben A. A whisper-game perspective on the family communication of DNA-test results: a retrospective study on the communication process of BRCA1/2test results between proband and relatives. Fam Cancer 2011;10:87-96.

13. Vos J, Oosterwijk JC, Gómez-García E, et al. Perceiving cancer-risks and heredity-likelihood in genetic-counseling: how counselees recall and interpret BRCA1/2-test results. Clin Genet 2011;79:207-218.

14. Vos J, Gómez-García E, Oosterwijk JC, et al. Opening the psychological black box in genetic counseling. The psychological impact of DNA-testing is predicted by the counsellees' perception, the medical impact by the pathogenic or uninformative BRCA1/2-result [published online ahead of print November 11, 2010]. Psychooncology doi: 10.1002/pon.1864.

15. Mellon S, Berry-Bobovski L, Gold R, Levin N, Tainsky MA. Communication and decision-making about seeking inherited cancer risk information: findings from female survivor-relative focus groups. Psychooncology 2006; 15:193-208.

16. Hallowell N, Ardern-Jones A, Eeles R, et al. Communication about genetic testing in families of male BRCA1/2 carriers and non-carriers: patterns, priorities and problems. Clin Genet 2005;67:492-502.

17. Keenan LA, Lesniak KT, Guarnaccia CA, Althaus B, Ethington G, Blum JL. Family environments of women seeking BRCA1/BRCA2 genetic mutation testing: an exploratory analysis. J Genet Couns 2004;V13:157-176.

18. van Oostrom I, Meijers-Heijboer H, Duivenvoorden HJ, et al. Experience of parental cancer in childhood is a risk factor for psychological distress during genetic cancer susceptibility testing. Ann Oncol 2006;17:1090-1095.

19. Lerman C, Trock B, Rimer BK, Jepson C, Brody D, Boyce A. Psychological side-effects of breast-cancer screening. Health Psychol 1991;10:259-267.

20. Thewes B, Meiser B, Hickie IB. Psychometric properties of the impact of event scale amongst women at increased risk for hereditary breast cancer. Psychooncology 2001;10:459-468

21. De Haes JCJM, Van Knippenberg FCE, Neijt JP. Measuring psychological and physical distress in cancer patients: structure and application of the Rotterdam Symptom Checklist. Br J Cancer 1990;62:1034-1038.

22. Hargrave T, Jennings G, Anderson W. The development of a relational ethics scale. J Marital Fam Ther 1991;17:145-148.

23. van Oostrom I, Meijers-Heijboer EJ, Duivenvoorden HJ, et al. Comparison of individuals opting for BRCA1/2 or HNPCC genetic susceptibility testing with regard to coping, illness perceptions, illness experiences, family system characteristics and hereditary cancer distress. Patient Educ Couns 2007;65:58-68.

24. van Dijk S, Otten W, van Asperen CJ, et al. Feeling at risk: how women interpret their familial breast cancer risk. Am J Med Genet A 2004;131A: $42-49$.

25. Vos J, Otten W, van Asperen C, Jansen A, Menko F, Tibben A. The 
counsellees' view of an unclassified variant in BRCA1/2: recall, interpretation, and impact on life. Psychooncology 2008;17:822-830.

26. Preacher KJ, Hayes AF. Asymptotic and resampling strategies for assessing and comparing indirect effects in multiple mediator models. Behav Res Methods 2008;40:879-889.

27. Fritz MS, MacKinnon DP. Required sample size to detect the mediated effect. Psychol Sci 2007;18:233-239.

28. Walter FM, Emery J, Braithwaite D, Marteau TM. Lay understanding of familial risk of common chronic diseases: a systematic review and synthesis of qualitative research. Ann Fam Med 2004;2:583-594.

29. Ponder M, Green JM. BRCA1 testing: some issues in moving from research to service. Psychooncology 1996;5:223-232.

30. Emery J, Kumar S, Smith H. Patient understanding of genetic principles and their expectations of genetic services within the NHS: a qualitative study. Community Genet 1998;1:78-83.

31. Peters JA, Biesecker BB. Genetic counseling and hereditary cancer. Cancer 1997;80:576-586.
32. Smith JA, Michie S, Allanson A, Elwy R. Certainty and uncertainty in genetic counselling: a qualitative case study. Psychol Health 2000;15:1-12.

33. Bylund C, Fisher C, Brashers D, Brown R, Edgerson S, Kissane D. Mothers' uncertainty about their daughters' breast cancer risk and prevention strategies (Abstract IPOS: A-509). Psychooncology 2010;19:141.

34. Geller G, Tambor ES, Chase GA, Holtzman NA. Measuring physicians tolerance for ambiguity and its relationship to their reported practices regarding genetic testing. Med Care 1993;31:989-1001.

35. Sarangi S. The language of likelihood in genetic-counseling discourse. $J$ Lang Social Psychol 2002;21:7-31.

36. Costalas JW, Itzen M, Malick J, et al. Communication of BRCA1 and BRCA2 results to at-risk relatives: a cancer risk assessment program's experience. A J Med Genet C Semin Med Genet 2003;119C: $11-18$.

37. Sermijn E, Goelen G, Teugels E, et al. The impact of proband mediated information dissemination in families with a BRCA1/2 gene mutation. $J$ Med Genet 2004;41:e23. 